\title{
Cowper-Symonds parameters estimation for ABS material using design of experiments with finite element simulation
}

\author{
Alexandre Luis Marangoni ${ }^{1 *}$ and Ernesto Massaroppi Junior ${ }^{2 * *}$ \\ ${ }^{1}$ Whirlpool S.A., Rio Claro, SP, Brazil \\ ${ }^{2}$ Laboratório de Mecânica Aplicada e Computacional, Departamento de Engenharia Mecânica, Escola de \\ Engenharia de São Carlos - EESC, Universidade de São Paulo - USP, São Carlos, SP, Brazil \\ *alexandre.marangoni@usp.br, **massarop@sc.usp.br
}

\begin{abstract}
Polymers exhibit significant strain rate dependence in their mechanical strength. The impact simulations accuracy is associated with the use of mechanical properties obtained at high strain rates. These properties are often not available to engineers introducing a risk on the product development step. This paper presents a method for adjusting the parameters of the Cowper-Symonds, used for a constitutive material model, through computational experiments carried out considering the simulation of the Izod impact test. The proposed adjustment method allows reducing the Izod impact strength error from $44 \%$ to $2.4 \%$.
\end{abstract}

Keywords: cowper-symonds, finite element analysis, izod, space filling design, strain rate.

\section{Introduction}

The structural strength of certain products and its components can not be easily evaluated by analytical calculations. For these cases the use of computational simulations performed with the Finite Element Method (FEM) is a frequently used tool for project aid, which generates significant gains in development time and prototypes cost reduction. The FEM is used to obtain a numerical solution of partial diferential equations in an approximate and discretized way. The vality domain of the diferential equation is subdivided in several subdomains, named elements, that are described by characteristics points, named nodes, normally positioned on the vertex of a polygon or a polyhedron. To each node is associated a polynomial shape function, whose linear combination is adopted as the solution in the element subdomain (approximate). The shape functions are fixed for a gived geometry and the solution functions become only dependent of the nodal value of the interesting variable (discretized) $)^{[1]}$. Furthermore, compatibility conditions are imposed to the solution functions in the interfaces between the elements. Among the possible diferential equations, those which relate the stress and strain in solid bodies submitted to forces, are commercially interesting and implemented in FEM softwares as, for exemple, LS-DYNA ${ }^{\circledR 2]}$. Before starting the FEM solver, it is necessary to define the domain, which is normally presented as a geometric description in a Computer Aided Design (CAD) software, and to generate the FEM mesh in an appropriated software as Altair HyperMesh 13.0 $0^{\circledast[3]}$. The simulation results are graphically represented in a post processing software as Altair HyperView 13.0 ${ }^{\circledR[4]}$.

The accuracy of the simulations results is strongly related to the finite element model quality, which includes the choice of the formulations of the elements that will be used to represent the structure, the interpretation of the boundary conditions, the constitutive model of the material and the solution method being used.
Impact simulations are performed to quantify the behavior of a mechanical structure under impact loads. The lack of information regarding material properties could lead to erroneous results and, as a consequence, wrong conclusions regarding the impact strength of the simulated part or product.

Polymers are widely used in the industry due to its good balance between cost and mechanical characteristics. Its mechanical strength varies as a function of the applied strain rate, which is associated with the polymer's viscoelastic behavior $^{[5]}$. The well-known Cowper-Symonds Equation 1 is frequently used to describe the material behavior at different strain rates ${ }^{[6]}$.

$$
\sigma D=\sigma E \cdot\left[1+\left(\frac{\dot{\varepsilon}}{C}\right)^{\frac{1}{P}}\right]
$$

Where $\sigma \mathrm{D}$ : dynamic stress; $\sigma \mathrm{E}$ : quasi-static stress; C e P: Cowper-Symonds equation's parameters and; $\dot{\varepsilon}$ : strain rate.

It is possible to find the Cowper-Symonds parameters with correlations above 0.95 . However, these parameters assume different values for different reference stresses, because each stress has its own sensitivity to strain rate, leading to different parameters in Cowper-Symonds equation. This feature can have an important effect on the numerical simulation of dynamic processes ${ }^{[7,8]}$.

The LS-DYNA ${ }^{\circledR}$ has several materials constitutive models and some of them use the Cowper-Symonds equation to include the strain rate effect at the yield stress.

Năstăsescu and Iliescu ${ }^{[9]}$ obtained values for the Cowper-Symonds parameters of a polymer through finite element simulations of the Izod impact test.

The mechanical properties of the material at high strain rates could be obtained experimentally by the use of 
a servo-hydraulic tensile testing machine or a Hopkinson bar testing ${ }^{[10]}$.

Computational experiments could be generated using space filling method, where the desired respose is evaluated under several configurations, obtained from an organized combination of the design factors levels. As the result a metamodel is generated to predict a system behavior as function of the studied factors ${ }^{[11,12]}$.

The objective of this work is to use design of experiments techniques to find and to adjust the Cowper-Symonds parameters of a LS-DYNA ${ }^{\circledR}$ material model, which can be used to improve the accuracy of the product level simulations.

\section{Materials and Methods}

The notched Izod impact test specimen, the impact hammer and the fixation jaw finite element model, showed at Figure 1, were created using the Altair HyperMesh 13.0 ${ }^{\circledR[3]}$ software in accordance to the ISO $180^{[13]}$ standard.

The LS-DYNA ${ }^{\circledR} *$ MAT_089 (Plasticity Polymer) material model was set to the specimen because the true stress-strain curve is used as input data, allowing the representation of the non-linear elastic behavior of most polymers. The strain rate effect could be applied at the yield or ultimate stress by the use of the $\mathrm{C}$ and $\mathrm{P}$ parameters of the Cowper-Symonds

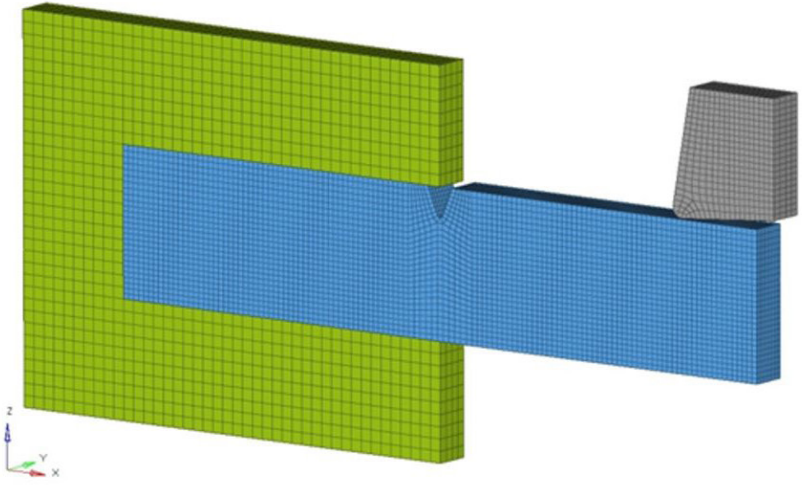

a)

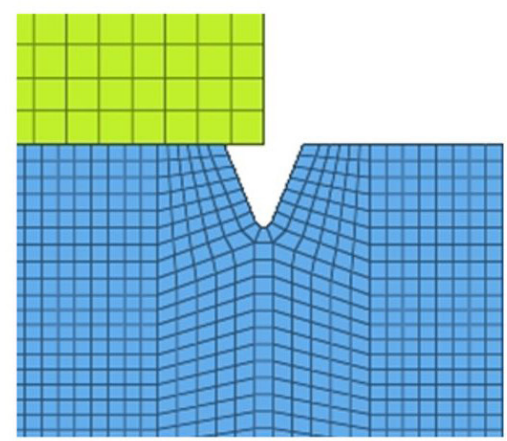

b)

Figure 1. Notched Izod Impact test FE model: (a) fixation jaw (green), specimen (blue) and impact hammer (gray); (b) Detail of the specimen mesh at the notch.

Table 1. ABS mechanical properties.

\begin{tabular}{cccc}
\hline Mechanical Property & Value & Unit & Source \\
\hline Young's Modulus & 2317.65 & $\mathrm{MPa}$ & Stress-strain curve \\
Yield Stress $\left(23^{\circ} \mathrm{C}\right)$ & 44.05 & $\mathrm{MPa}$ & Stress-strain curve \\
Yield Strain $\left(23^{\circ} \mathrm{C}\right)$ & 3.34 & $\%$ & Stress-strain curve \\
Izod Impact Strengh & 21.691 & $\mathrm{~kJ} / \mathrm{m}^{2}$ & Datasheet \\
\hline
\end{tabular}

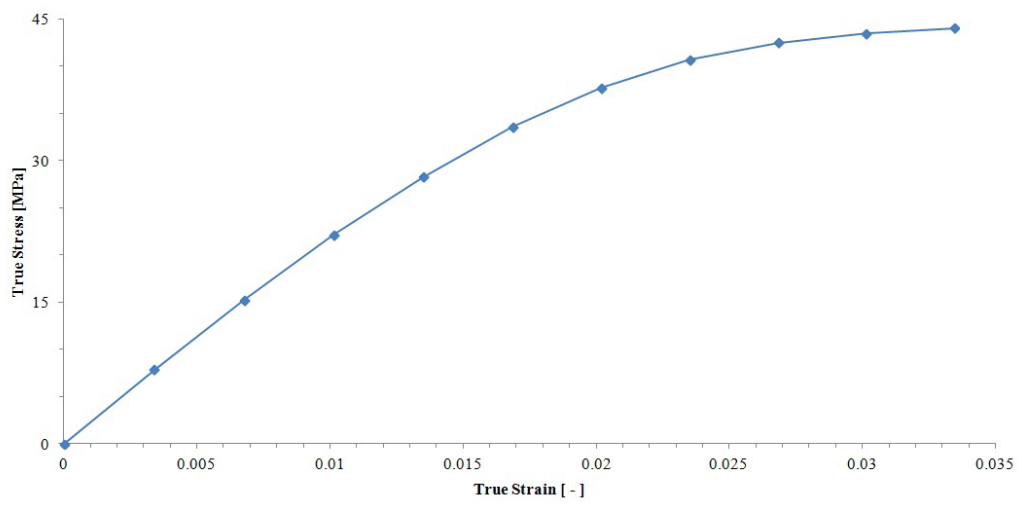

Figure 2. ABS stress-strain curve. Source: Campus ${ }^{\circledR[14]}$. 
equation or as a load curve at the failure strain by the use of a natural $\log$ of the strain rate by the true strain to failure.

The mechanical properties and the stress-strain curve of an ABS (Acrylonitrile butadiene styrene) grade used on this study were obtained from the CAMPUS ${ }^{\circledR[14]}$ (Computer Aided Material Preselection by Uniform Standards) database, and are showed at Table 1 and Figure 2, respectively.

For the material model *MAT_89 an internal check is performed by LS-DYNA ${ }^{\circledR}$ and the yield occurs when the current stress-strain curve slope becomes lower than the value defined at the elastic model field ${ }^{[15]}$.

The rigid material (*Mat_020) was used at the jaw and impact hammer. The material density was calculated in order to result into a $15 \mathrm{~kg}$ impact hammer mass $(\mathrm{m})$. The ABS Izod absorbed energy is $2.0 \mathrm{~J}$ which correspond to an impact energy $\left(E_{K}\right)$ of $2.7 \mathrm{~J}$. The impact hammer initial velocity (v) of $600 \mathrm{~mm} / \mathrm{s}$ was calculated as shown in Equation 2.

$$
v=1000 \times \sqrt{2 E_{K} / m}
$$

A space filling design experiment, considering as factors the parameters $\mathrm{C}$ and $\mathrm{P}$ of the Cowper-Symonds equation, was carried out to adjust these material properties due to its capability for modeling non-linear phenomena.

The factors levels were estimated through simulations considering arbitrary values to $\mathrm{C}$ and $\mathrm{P}$. The impact test simulation was also performed without any strain rate effect.

The computational experiment was generated using the data analysis software SAS JMP $10.0^{\circledR[11]}$, considering the uniform design and 10 simulations, as showed on Table 2. Although the experimental generation uses the range of values for the factors $\mathrm{C}$ and $\mathrm{P}$, here they will be presented at normalized form between -1 and 1 for industrial confidence purposes.

The Altair HyperMesh $13.0^{\circledR}$ software was used to generate 10 finite element model files considering the combination of the $\mathrm{C}$ and $\mathrm{P}$ factors. The simulations were performed at LS-DYNA ${ }^{\circledR}$ considering an impact time of $0.015 \mathrm{~s}$. The final hammer velocity value obtained at the post-processing, performed by Altair HyperView 13.0 ${ }^{\circledR}$ software, was used at Equation 3 to calculate the kinetic energy variation.

Table 2. Normalized parameters for each simulation of the space filling experiment.

\begin{tabular}{ccc}
\hline Simulation & $\mathbf{C}$ & $\mathbf{P}$ \\
\hline 1 & -0.703 & 0.836 \\
2 & 0.310 & 0.370 \\
3 & -0.898 & 0.637 \\
4 & 0.897 & 0.701 \\
5 & 0.507 & 0.775 \\
6 & -0.288 & 0.432 \\
7 & 0.121 & 0.966 \\
8 & -0.115 & 0.901 \\
9 & 0.704 & 0.563 \\
10 & -0.512 & 0.502 \\
\hline
\end{tabular}

The absorbed energy by the specimen was calculated through Equation 4.

$$
\Delta E_{K}=E_{K}-\frac{1}{2} m \times v_{f}^{2}
$$

Where $\Delta E_{K}$ : kinetic energy variation; $E_{K}$ : initial kinetic energy of the hammer; $m$ : hammer mass and; $v_{F}$ : final velocity of the hammer.

$$
E_{a b s}=\Delta E_{K} / A_{f r}
$$

Where $E_{A B S}$ : specific absorved energy; $\Delta E_{K}$ : kinetic energy variation; and $A_{F R}$ : fractured area of the specimen.

The software SAS JMP $10.0^{\circledR}$ was also used to analyze the experiment results. A metamodel was adjusted by the Gaussian method. The desirability feature was used to reach an absorbed energy of $21.691 \mathrm{~kJ} / \mathrm{m}^{2}$ through the combination of the values of the factors $\mathrm{C}$ and $\mathrm{P}$. The obtained combination of the factors was then used in another simulation to check the metamodel adjustment quality/accuracy.

\section{Results and Discussions}

The final hammer velocity obtained at the simulation without the strain rate effects was $554.95 \mathrm{~mm} / \mathrm{s}$. The absorbed energy by the specimen was $39.026 \mathrm{~kJ} / \mathrm{m}^{2}$.

A fractured specimen and the respective plot of the hammer velocity as function of the impact time are shown on Figures $3 \mathrm{a}$ and $3 \mathrm{~b}$, respectively. The hammer velocity was reduced from $600 \mathrm{~mm} / \mathrm{s}$ to $517.758 \mathrm{~mm} / \mathrm{s}$. Despite an incomplete fracture of the specimen was observed at impact time of $0.015 \mathrm{~s}$, the asymptotic behavior of the curve after $0.014 \mathrm{~s}$ indicates that the hammer velocity will not be significantly changed by the use of a higher simulation termination time. Table 3 shows the absorbed energy calculated through Equation 4 for the all simulations of the experiment.

Figure 4 shows the absorbed impact energy obtained by the simulation as a function of the predicted results by the metamodel. The quality of the metamodel can be verified by the proximity of the points to the dashed red line. For this case, as predicted, only one point showed a significant distance from the dashed line. Although the computational experiment was carried out with a reduced number of simulations, the resultant metamodel has shown a satisfactory quality of fit.

The prediction energy model as a function of the $\mathrm{C}$ and $\mathrm{P}$ parameters behavior are shown on Figure 5 . The normalized values of -0.378 and 0.5107 for the $C$ and $P$ parameters, respectively, were obtained through the use of the SAS JMP $10.0^{\circledR}$ Desirability function used to match the target energy of $21.691 \mathrm{~kJ} / \mathrm{m}^{2}$. The impact simulation result for this case is shown on Figure 6. A final velocity of $515.016 \mathrm{~mm} / \mathrm{s}$ of the impact hammer resulted on an absorbed energy of $22.209 \mathrm{~kJ} / \mathrm{m}^{2}$, which is $2.4 \%$ higher than the target impact value as shown at the polymer datasheet. 

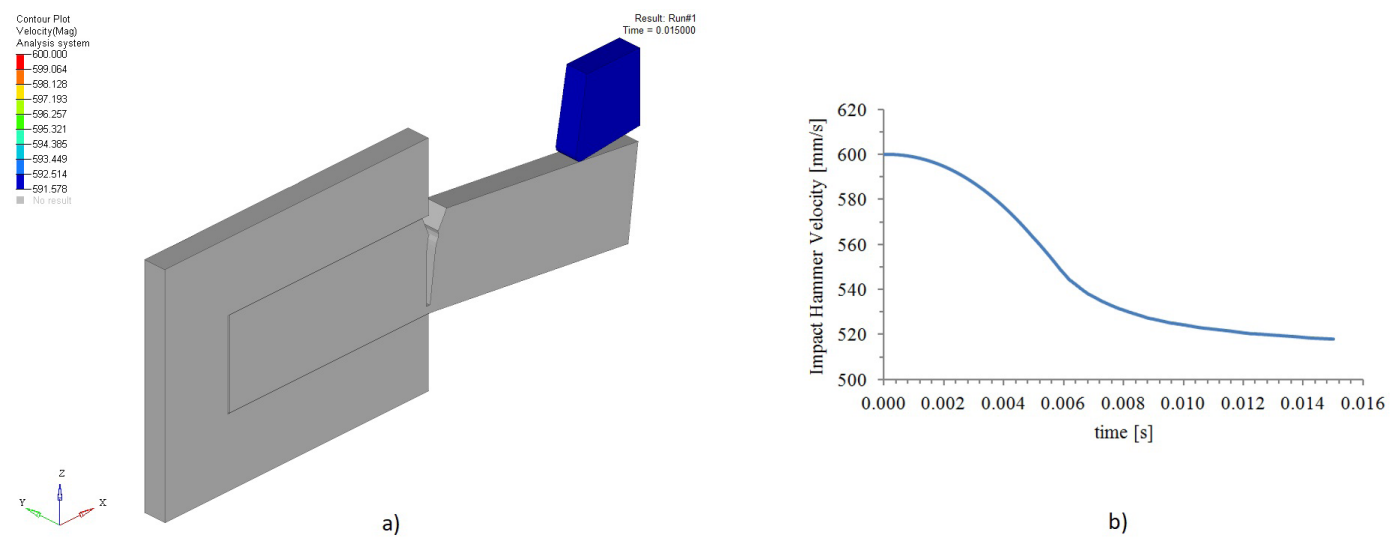

Figure 3. Simulation number 1: (a) Fractured virtual specimen; (b) Impact hammer velocity (mm/s) as function of the time (s).

Table 3. Final impact hammers velocities and absorbed energy by the specimen for all simulations.

\begin{tabular}{cccc}
\hline Simulation number & Final Hammer Velocity $(\mathbf{m m} / \mathbf{s})$ & Final Hammer Kinetic Energy $(\mathbf{J})$ & Absorbed Energy $\left(\mathbf{k J} / \mathbf{m}^{2}\right)$ \\
\hline 1 & 517.758 & 2.011 & 21.545 \\
2 & 517.171 & 2.006 & 21.688 \\
3 & 516.591 & 2.001 & 21.828 \\
4 & 518.917 & 2.020 & 21.264 \\
5 & 518.936 & 2.020 & 21.259 \\
6 & 516.562 & 2.001 & 21.835 \\
7 & 519.322 & 2.023 & 21.165 \\
8 & 519.004 & 2.020 & 21.243 \\
9 & 519.831 & 2.027 & 21.041 \\
10 & 516.779 & 2.003 & 21.783 \\
\hline
\end{tabular}

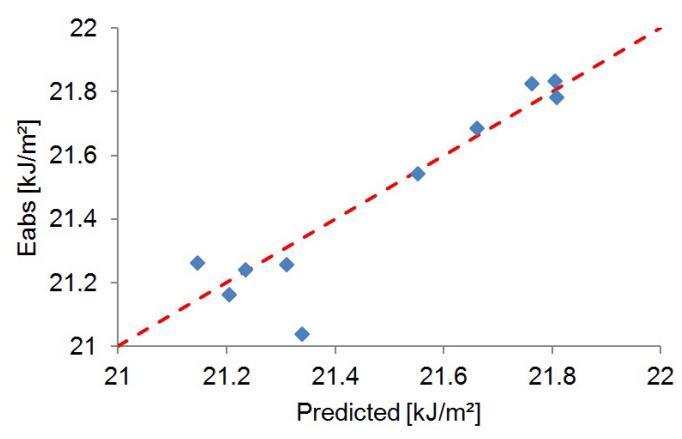

Figure 4. Absorbed energy values (Eabs) as function of the predicted values by the Gaussian Modeling.

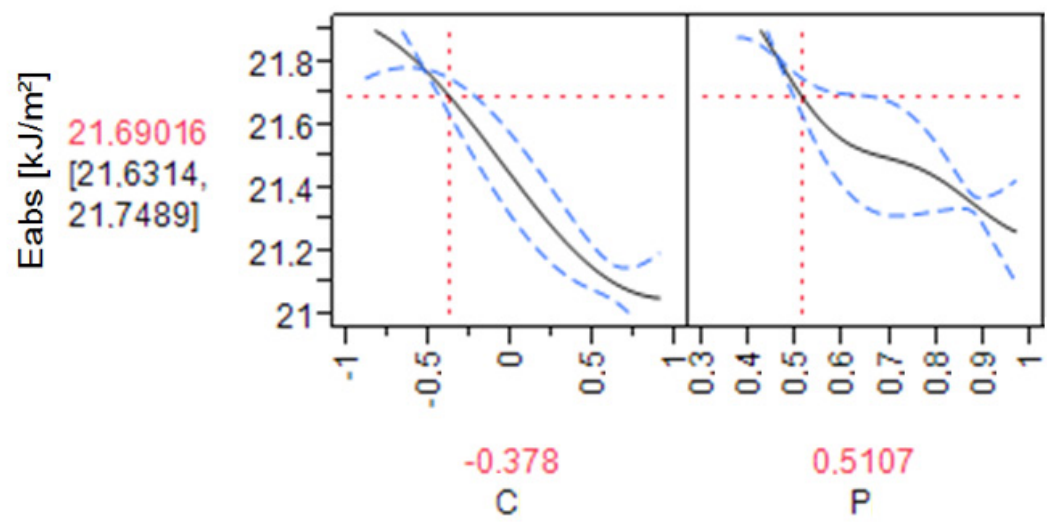

Figure 5. Prediction of specimen energy absorption as function of the normalized $\mathrm{C}$ and $\mathrm{P}$ parameters. 


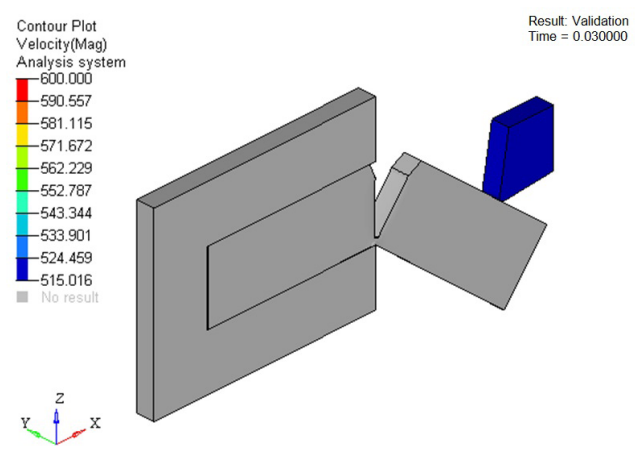

a)

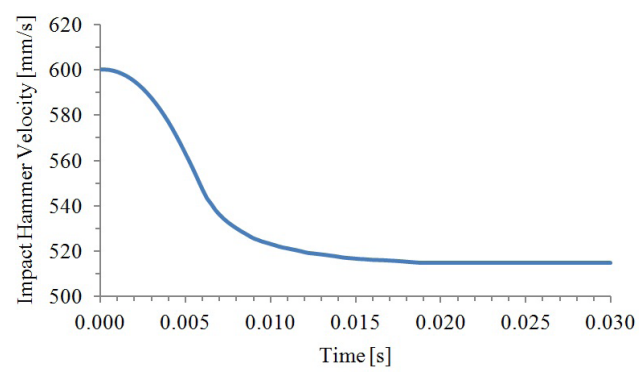

b)

Figure 6. Results of the validation simulation: (a) Fractured Specimen; (b) Impact hammer velocity (mm/s) as function of the time (s).

\section{Conclusions}

While the execution of an Izod impact test simulation without considering any material strain rate effect led to a $44 \%$ error relative to the Izod result shown at polymer datasheet, the absorbed energy error was significantly reduced to $2.4 \%$ with the use of the adjusted Cowper-Symonds strain rate parameters.

Based on this result it can be concluded that the adjustment method of Cowper-Symonds equation parameters for the LS-DYNA ${ }^{\circledR} *$ MAT_089 (Plasticity Polymer) material model through the use of a computational space filling design experiment was effective. This methodology could improve the simulation results in cases where the complete dynamic material characterization is not available.

\section{Acknowledgements}

The authors are grateful to Whirpool S.A. and to Laboratory of Applied and Computational Mechanical of the Departament of Mechanical Engineering of the School of Engineering of São Carlos of the University of São Paulo for providing the necessary computational resources.

\section{References}

1. Zienkiewicz, O. C., \& Taylor, R. L. (2000). The finite element $\operatorname{method}$ (Vol. 1, 5th ed., 689 p.). Oxford: Butterworth Heinemann.

2. Livermore Software Technology Corporation. (2014). $L S-D Y N A^{\circledR}$ keyword user's manual, revision 5471 (Vol. 1). Livermore: LSTC.

3. Altair. (2014). HyperMesh 13.0 manual. Retrieved in 1 April 2016, from http://www.altairhyperworks.com/product/ HyperMesh

4. Altair. (2014). HyperView 13.0 manual. Retrieved in 1 April 2016, from http://www.altairhyperworks.com/product/ HyperView

5. Xiao, X. (2008). Dynamic tensile testing of plastic materials. Polymer Testing, 27(2), 164-178. http://dx.doi.org/10.1016/j. polymertesting.2007.09.010.

6. Peixinho, N., \& Doellinger, C. (2010). Characterization of dynamic material properties of light alloys for crashworthiness applications. Materials Research, 13(4), 471-474. http://dx.doi. org/10.1590/S1516-14392010000400008.
7. Peixinho, N., \& Pinho, A. (2007). Study of viscoplasticity models for the impact behavior of high-strengh steels. Journal of Computational and Nonlinear Dynamics, 2(2), 114-123. http://dx.doi.org/10.1115/1.2447129.

8. Alves, M. (2000). Material constitutive law for large strains and strain rates. Journal of Engineering Mechanics, 126(2), 215-218. http://dx.doi.org/10.1061/(ASCE)0733-9399(2000)126:2(215).

9. Năstăsescu, V., \& Iliescu, N. (2010). Upon accompanying of the experimental testing of materials by numerical analysis with FEM. Acta Technica Napocensis - Applied Mathematics and Mechanics, 2(53), 173-178. Retrieved in 1 April 2016, from artens2010.utcluj.ro/acta\%20tehnica\%20nr53\%20 vol2\%202010/10.doc

10. Zrida, M., Laurent, H., Grolleau, V., Rio, G., Khlif, M., Guines, D., Masmoudi, N., \& Bradai, C. (2010). High-speed tensile tests on a polypropylene material. Polymer Testing, 29(6), 685-692. http://dx.doi.org/10.1016/j.polymertesting.2010.05.007.

11. SAS Institute. (2010). User Guide - SAS JMP 10.0. Cary: SAS Institute.

12. Baco, S. B. (2016). Uso de experimentos computacionais no desenvolvimento de produtos: um estudo de caso na indústria de linha branca (Dissertação de mestrado). Universidade Federal de São Carlos, São Carlos.

13. International Standard Organization. (2000). ISO 180:2000 - Plastics -- Determination of Izod impact strength. Geneva: ISO.

14. Computer Aided Material Preselection by Uniform Standard. (2016). Plastics Material Database. Frankfurt: Campus. Retrieved in 1 April 2016, from http://www.campusplastics. com

15. Lobo, H., \& Croop, B. (2009). A robust methodology to calibrate crash material models for polymers. In NAFEMS World Congress (14 p). Ithaca: DatapointLabs. Retrieved in 1 April 2016, from http://www.datapointlabs.com/testpaks/2009/ NAFEMS09.pdf 